\title{
Chapter 37 \\ Variation of Permeability of Viscous Fluid During Liquefaction Model Testing
}

\author{
Tetsuo Tobita
}

\subsection{Summary}

In dynamic centrifuge modelling, to resolve conflicts in scaling of time between dynamic and diffusion events, viscous fluids are used to reduce a model's permeability. Recently, with the ease of its handling, methylcellulose (MC) solution is commonly used (Stewart et al. 1998). The author conducted constant head permeability tests of Toyoura sand by varying the fluid viscosity, paying attention to transient changes in its permeability and found that the permeability of sand with MC solution continuously decreased with the fluid passing, whereas it remained constant for purified water. Then, by modelling of models of the liquefaction model in centrifuge testing, the effect of permeability reduction is monitored and was confirmed that the effect is relatively minor. However, this is thought to be one of the sources of epistemic errors in centrifuge modelling.

\subsection{Essay}

Constant head permeability tests were conducted with a particular focus on the transient changes of permeability with viscous fluids made of methylcellulose (MC) solution. Tested fluid viscosities were 20, 44 and 60 times that of purified water (Fig. 37.1). Results of the constant head tests showed that the permeability tends to degrade with the increasing volume of passing fluid. The effect might seriously affect the physical modelling in practice. Results of the constant head

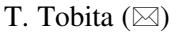

Department of Civil Engineering, Kansai University, Osaka, Japan

e-mail: tobita@kansai-u.ac.jp

(C) The Author(s) 2020 

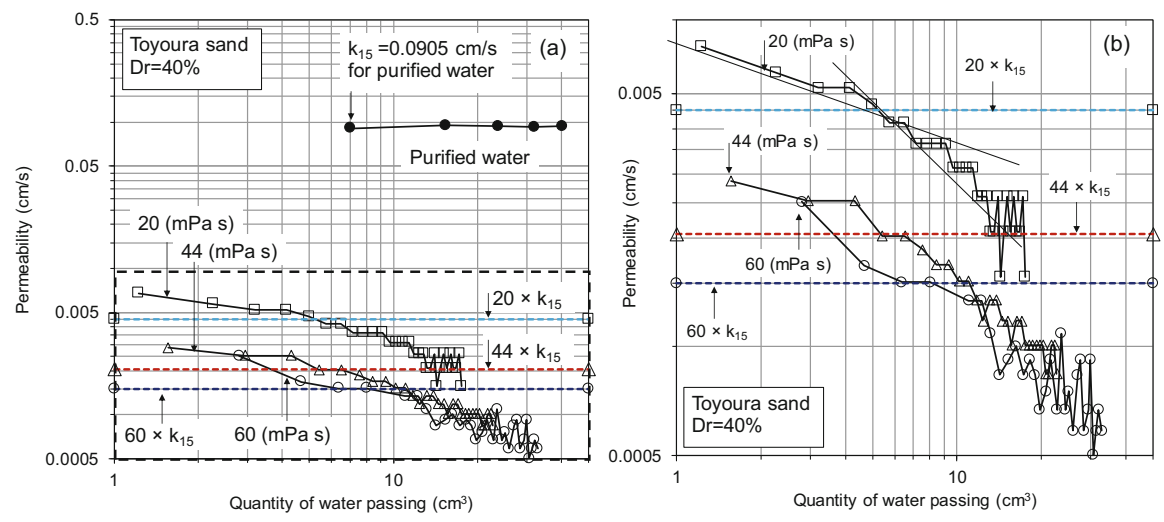

Fig. 37.1 Variation of the permeability with quantity of passing water for Toyoura sand $\left(D_{\mathrm{r}}=40 \%\right)$ : (a) showing all curves including permeability of purified water and (b) showing curves of viscous fluids only

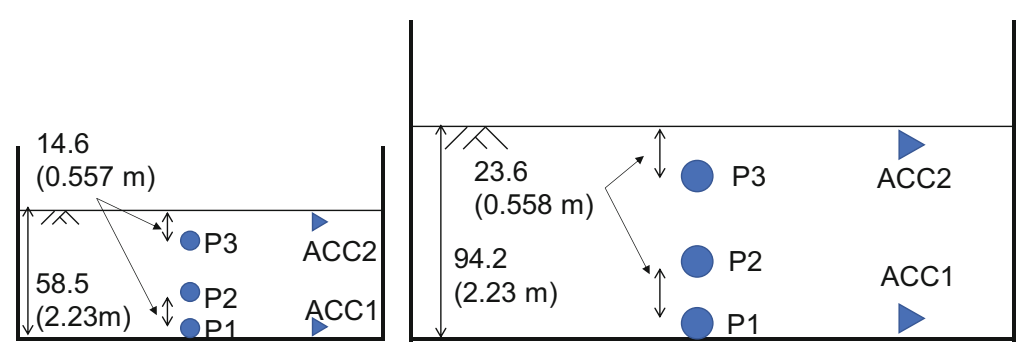

(a) $38.1 \mathrm{G}$

(b) $23.7 \mathrm{G}$

Fig. 37.2 Model dimensions and sensors' location for "modelling of models" centrifuge tests: (a) $38.1 \mathrm{G}$ and (b) $23.7 \mathrm{G}$

tests showed that the derived curves of permeability versus the volume of passing fluid were comprised of two segments. On the first slope, permeability continuously decreased at an almost constant rate regardless of the viscosity of the fluid until specific volumes of viscous fluid passing being reached at which point the curves reached a breakpoint and the second slope started. The rate of degradation was reduced less than $50 \%$. The first slope of the curve may correspond to a complete coverage of pores near the surface in the sand specimen by MC fibres. From the above observation, it may be concluded that the permeability with MC solution drastically decreases with the quantity of viscous fluid passing.

Then to see the effects of this variation of permeability, centrifuge model tests were conducted under two different centrifugal accelerations: $38.1 \mathrm{G}$ and $23.7 \mathrm{G}$ (Fig. 37.2). These $\mathrm{G}$ levels were determined by the scaling law of time for dynamic phenomena using MC solution of 38.1 and $23.7 \mathrm{mPa}$ s as a pore fluid. A centrifugal acceleration at $1 / 3$ of ground thickness from the surface was monitored, and the $G$ level was maintained during the experiment so that the error of confining stress due 

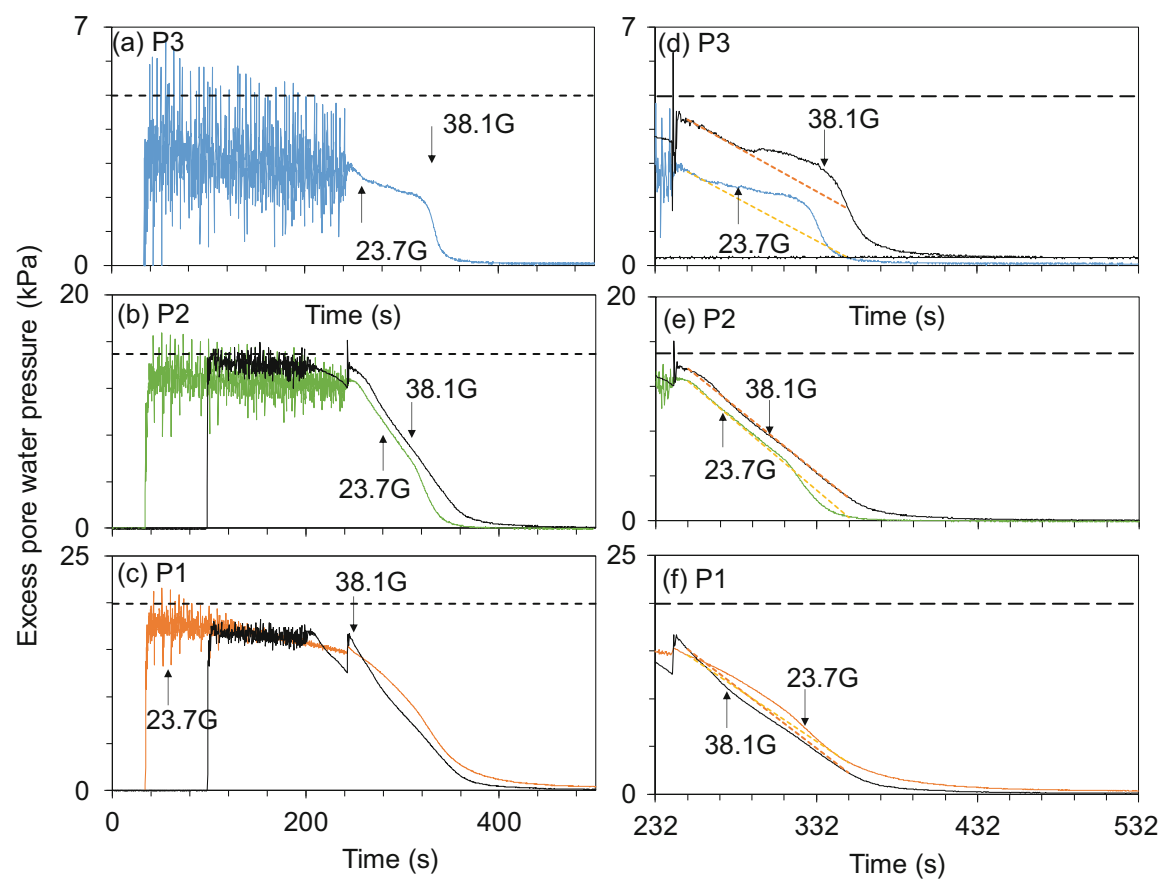

Fig. 37.3 Time histories of excess pore water pressure: (a) P3, (b) P2, and (c) P1 and (d)-(f) for 232-532 s. Dotted horizontal line indicates the initial effective vertical stress

to radial acceleration field can be minimized. Attention was given to the rate of pore pressure dissipation (Fig. 37.3). What was found from the centrifuge model tests are that the curves in the dissipation phase deviates from the linear segments in both cases of $38.1 \mathrm{G}$ and $23.7 \mathrm{G}$ (Fig. 37.3d). This may indicate that as pore pressure dissipates from the ground ejected pore water may be accumulated near the ground surface because of the possible effect of clogging of MC solutions.

By assuming that the settled volume of the ground after shaking was equal to the volume of fluid ejected from the ground, the quantity of passing water was estimated to be 4.29 and $11.3 \mathrm{~cm}^{3}$, respectively, for the cases of $38.1 \mathrm{G}$ and $23.7 \mathrm{G}$. With these numbers and results of the constant head test results (Fig. 37.1), for the case of $38.1 \mathrm{G}$ in which the MC solution of $38.1 \mathrm{mPa}$ s was used, the effect of the degradation of permeability would be minor, while for the case of $23.1 \mathrm{G}(23.1 \mathrm{mPa})$ about $40 \%$ of reduction in permeability was expected.

We conclude that care should be taken if the duration of the diffusion process or settlements after liquefaction is of particular interest in testing a model with MC solutions. Duration times can be larger than that of a prototype because of the possible clogging effect of the MC fibres. The degree of clogging may depend on the density of MC fibres in a fluid. Thus, care should also be taken to choose a type of $\mathrm{MC}$ which gives the lowest density of fibres in a viscous fluid of a certain viscosity. 
Acknowledgement The author thanks Mr. Kenta Yokoyama, a former undergraduate student at Kansai University, for conducting the constant head permeability tests and centrifuge tests as part of his graduation thesis.

\section{Reference}

Stewart, D. P., Chen, Y.-R., \& Kutter, B. L. (1998). Experience with the use of methylcellulose as a viscous pore fluid in centrifuge models. Geotechnical Testing Journal, 21(4), 365-369.

Open Access This chapter is licensed under the terms of the Creative Commons Attribution 4.0 International License (http://creativecommons.org/licenses/by/4.0/), which permits use, sharing, adaptation, distribution and reproduction in any medium or format, as long as you give appropriate credit to the original author(s) and the source, provide a link to the Creative Commons license and indicate if changes were made.

The images or other third party material in this chapter are included in the chapter's Creative Commons license, unless indicated otherwise in a credit line to the material. If material is not included in the chapter's Creative Commons license and your intended use is not permitted by statutory regulation or exceeds the permitted use, you will need to obtain permission directly from the copyright holder. 